\title{
ANALYSIS OF FACTORS AFFECTING FRESH MILK CONSUMPTION AMONG THE MID - COUNTRY CONSUMERS
}

\author{
AEN De Alwis, JC Edirisinghe and AMTP Athauda \\ Department of Agribusiness Management, Faculty of Agriculture and Plantation Management, \\ Wayamba University of Sri Lanka, Makandura, Gonawila (NWP).
}

Accepted: $6^{\text {th }}$ October 2009

\begin{abstract}
This study focused on analysing the consumer attitudes, demographic and economic factors that affecting fresh milk consumption among the mid-country consumers of Sri Lanka. Data were collected through a consumer survey conducted in Kandy district at randomly selected super markets, groceries, milk bars and retail shops. Factor analysis was carried out in order to weigh up the consumer attitudes and factor scores were introduced to the final model as independent variables which can be categorized as cost and usage, nutrition, sensory factors and availability. An ordered logistic regression was carried out to find out the relationships between number of demographic and socio-economic characteristics of consumers such as age, gender, level of education, income, size and composition of the household, ethnic group and presence of diseases that affect fresh milk consumption. Results from estimation of a ordered logistic regression model of consumption show age of the respondent, cost and usage related attitudinal factor and Nutrition related attitudinal factors are the key determinants of milk consumption levels; however, household monthly income, health problems affect on fresh milk consumption and level of education play a more important role in consumption. Finally, these findings suggest the marketing strategies which are most suitable to fit with the consumer expectations.
\end{abstract}

Key words: Attitudes, Fresh milk consumption, Ordered Logistic Regression, Sri Lanka

\section{INTRODUCTION}

The dairy industry is one of the most important industries of the country that has tremendous potentials in developing the economy. Milk is a unique food item that needs to be available in the market without any shortage since it plays a key role in infant feeding and alleviating nutritional poverty in all other age groups (MLDRI 1995). It has been perceived by consumers as an important source of nutrients, especially calcium for good bone and teeth health (Bus and Worsley 2003; Wham and Worsley 2003). Recent medical researches have found out that there are positive correlations between fresh milk consumption and the reduction of risk for coronary heart diseases and strokes (Shaper et al 1991; Massey 2001). Fresh milk can also provide benefits in weight management (Zemel 2002).

In Sri Lanka fresh milk consumption is not much significant because majority of the consumers $(63 \%)$ are used to consume full cream milk powder. Fresh milk consumption is about one percent of the overall milk consumption of the country (Central Bank of Sri Lanka 2005a). In spite of the fact that the Medical Research Institute (MRI) recommends a consumption level of $60-65 \mathrm{~kg}$ per person per year, the per capita availability of fresh milk is only about $36 \mathrm{~kg}$ per person per year and it has been confirmed that Sri Lanka has the lowest milk consumption in South Asia at present (MLDEI 2000).

*Corresponding author:edi_has@yahoo.co.uk

Paper presented at the 2nd National Symposium, Faculty of Agriculture, University of Ruhuna
Fresh milk, as a drink, both in and out of the home, has endured ruthless competition from soft drinks and powdered milk. The range of products in the category of soft drinks, packaging and availability has widened and their low material costs enable them to be extensively promoted (Wham and Worsley 2003). Also, there are huge campaigns to promote the consumption of powdered milk in different brand names and hence there is a significantly higher demand for powdered milk.

Though, the demand for powdered milk is high, there is a particular problem that modern science has largely ignored, which is the nutritive value of heat - labile elements in milk. Some nutrients are destroyed by heat and available only in raw form and some of the factors transmitted by milk are thermo - labile. Therefore, the best milk from the nutritional stand point is "fresh milk" (Schmid 2006).

Several studies have shown that the consumption of fresh milk is partly affected due to poor availability, health problems and hygienic conditions. In addition, lifestyle factors have also influenced the habitual food choices of the consumer and some others studies have illustrated that membership of social category such as gender, age, education, occupational status and ethnicity may influence food selection behaviours and the attitudes and believes on which they depend on (Wham and Worsley 2003; Bus and Worsley 2003). Factors influencing consumer attitudes and acceptance of a product may include product attributes, price as 
well as consumer's social demographic and possible interaction between these factors (Peng et al 2006).

According to Information Theory (Nelson 1970; Darby and Karni 1973), consumers assess the quality and attributes of a commodity based on three types of information they obtain about that particular commodity namely Search, Experience and Credence characteristics. Search characteristics are those that can be assessed prior to purchase (e. g. appearance of the product), Experience characteristics are those that can be obtained as the product is consumed (e.g. taste of a product) and Credence characteristics are those that can not be discerned by normal use (e.g. healthiness of a product) (Peng et al 2006).

Several studies have demonstrated that attitudes and beliefs about a particular food predict their consumption and these appear to overrule other lifestyle factors (Wham and Worsley 2003). There may be attitude factors underlying declining fresh milk consumption that require attention and this may lead to the development of interventions to promote more healthful behaviours.

In this study attention was paid to identify demographic, economic and attitudinal factors that may influence fresh milk consumption of the mid country consumers in order to help to trace the opportunities and potentials in milk industry in Sri Lanka. Increased milk consumption will have strong positive effects on opportunities for domestic production giving the clear comparative advantage that domestic production hold for supplying fresh milk demand.

\section{MATERIALS AND METHODS}

In order to arrive at the aforesaid aims, the study was methodically developed to hypothesize that the fresh milk consumption behaviour is associated with demographic, economic and attitudinal characters of the consumers. Thus, to see the impact of these factors on the consumption of fresh milk, a regression analysis was developed as below.

However, there were two issues that needed to be resolved in order to carry out such a regression analysis. First, was the issue of measuring the attitudinal factors as this is associated with number of difficulties, including "unobservable nature" and "subjectivity" of behaviour among individuals. To resolve this difficulty, the study resorted to alternative ways of developing appropriate techniques to Consumption $=\int($ Demographic, Economic, Attitudes $)$

avoid losing too much information.

Through a review of past studies on fresh milk consumption (Peng et al 2006; Bus and Worsley
2003), 11 statements were used to represent attitudinal factor in the above regression. Each statement was given a score by each consumer on a Likert scale of 1 to 7 where, 1 represents strong disagreement and 7 refers to strong agreement (Table 1). To avoid the difficulty in handling a large number of statements in the regression, a factor analysis was conducted to reduce the number of statements in to a smaller number of factors via principle component analysis with Varimax rotation (Malhotra 2005)

The co-variation among the variables was described in terms of a small number of common factors plus a unique factor for each variable. The factor model can be represented as follows:

$$
\chi_{i}=\mathrm{A}_{i 1} F_{1}+\mathrm{A}_{i 2} F_{2}+\mathrm{A}_{i 3} F_{3}+\ldots \ldots \ldots \ldots . . . \mathrm{A}_{i m} F_{m}+V_{i} U_{i}
$$

Where,

$=i^{\text {th }}$ standardized variable

$A_{i j}=$ Standardized multiple regression co-efficient of variable $i$ on common factor $j$

$\mathrm{F}=$ Common factor

$V_{i}=$ Standardized regression co-efficient of variable $i$ on $U$

$U_{i}=$ Unique factor for variable $i$

$m=$ Number of common factors

$\chi_{i}$

The factor scores were calculated for the $i^{\text {th }}$ factor as,

$$
F_{i}=W_{i 1} \chi_{1}+W_{i 2} \chi_{2}+W_{i 3} \chi_{3}+\ldots \ldots \ldots+W_{i k} \chi_{k}
$$

Where,

$F_{i}=$ Estimate of $i^{\text {th }}$ factor

$W_{i}=$ Weight of factor score coefficient

$k=$ Number of variables

Each factor formed a score that serves as an independent attitude variable in the above fresh milk consumption behaviour model.

The second issue that had to be resolved was the issue of measuring the consumption in a reasonable manner as the exact consumption levels were hard to obtain. However, since the consumers were able to correctly specify their frequency of consumption, it was used as the dependent variable in the model. As the consumer's frequency of fresh milk consumption was categorized into four categories which suits for ordinal rankings, the use of a technique that can handle this type of qualitative variable was imperative and therefore ordered logistic regression was applied in this analysis.

Degree of fresh milk consumption of individual consumers was quasi- observed and can be decom- 
posed in to a deterministic component and additive stochastic component (Borooah 2002; Pampel 2000)

$$
D_{i}=\sum_{k=1}^{k} \beta_{\kappa} X_{\imath \kappa}+\Sigma_{i}=Z_{i}+\sum_{i}^{\text {Where }}
$$

$\mathrm{D}_{\mathrm{i}}$ was the consumer's degree of fresh milk consumption,

$\mathrm{k}$ factors (determining variable) whose values, for individual $\mathrm{i}$,

were $X_{i k}, k=1 \ldots k, \beta=k$ is the coefficient associated with the $\mathrm{k}^{\text {th }}$ variable.

The relationship between $D_{i}$ and the ordinal likelihood ranking $Y$ was a function of cut-off points or thresholds, $\delta$ ' s which are known and can be estimated along with $\beta$ 's. Hence the dependent variable can be expressed as,

$$
\begin{array}{ll}
Y_{i}=1 & \\
Y_{i}=2 & \text { if } D_{i} \leq \delta_{1} \\
Y_{i}=3 & \text { if } \delta_{1} \leq D_{i} \leq \delta_{2} \\
Y_{i}=4 & \text { if } \delta_{2} \leq D_{i} \leq \delta_{3}
\end{array}
$$

The probabilities of $Y_{i}$ if $D_{i} \geq \delta_{3}$ taking values 1 , 2,3 , and 4 given by,

\begin{tabular}{|c|c|}
\hline Statement & $\begin{array}{l}\text { Abbrevia- } \\
\text { tion }\end{array}$ \\
\hline Always purchase milk products available in high price & HCOST \\
\hline Packaging should be in high quality & QPACK \\
\hline Brand is a very important factor & BRAND \\
\hline Taste is very important & TASTE \\
\hline $\begin{array}{l}\text { Fresh milk is more tasty than other processed milk prod- } \\
\text { ucts }\end{array}$ & FTAST \\
\hline Appearance of the product is important & APEAR \\
\hline $\begin{array}{l}\text { Always purchase milk products with high nutritional } \\
\text { value }\end{array}$ & HINEU \\
\hline $\begin{array}{l}\text { Fresh milk is convenient source of many important nutri- } \\
\text { ents }\end{array}$ & CONEU \\
\hline $\begin{array}{l}\text { Nutritional quality of fresh milk is much higher than } \\
\text { processed milk products }\end{array}$ & NEQUL \\
\hline $\begin{array}{l}\text { Poor availability of fresh milk creates me a barrier for } \\
\text { consumption }\end{array}$ & PORAV \\
\hline $\begin{array}{l}\text { Seek to purchase anyhow ( without considering difficul- } \\
\text { ties) }\end{array}$ & ANYHW \\
\hline
\end{tabular}

$$
\begin{aligned}
& \operatorname{Pr}\left(\mathrm{Y}_{i}=1\right)=\operatorname{Pr}\left(\varepsilon_{i} \leq \delta_{1}-\mathrm{Z}_{i}\right) \\
& \operatorname{Pr}\left(\mathrm{Y}_{i}=2\right)=\operatorname{Pr}\left(\delta_{1}-\mathrm{Z}_{i} \leq \varepsilon_{i} \delta_{2}-\mathrm{Z}_{i}\right) \\
& \operatorname{Pr}\left(\mathrm{Y}_{i}=3\right)=\operatorname{Pr}\left(\delta_{2}-\mathrm{Z}_{i} \leq \varepsilon_{i} \delta_{3}-\mathrm{Z}_{i}\right) \\
& \operatorname{Pr}\left(\mathrm{Y}_{i}=4\right)=\operatorname{Pr}\left(\varepsilon_{i} \geq \delta_{3}-\mathrm{Z}_{i}\right)
\end{aligned}
$$

The marginal effects of the independent variables on the probabilities were used to explain the model, and they were not identical with coefficients estimated and then depend on the values of all independent variables. The marginal effects of the vari-

Table 1: Attitude statements used for factor analysis ables were calculated for each of the probabilities as follows.

$$
\begin{aligned}
& \frac{\partial \operatorname{Pr}(Y=1)}{\partial X_{i k}}=\frac{d}{d_{z i}}\left[\Lambda\left(\delta_{1}-Z_{i}\right)\right] \frac{\partial Z_{i}}{\partial \chi_{i k}}=-\Lambda^{\prime}\left(\delta_{i}-Z_{i}\right) \beta_{k} \\
& \frac{\partial \operatorname{Pr}(Y=3)}{\partial X_{i k}}=\frac{d}{d_{z i}}\left[\Lambda\left(\delta_{3}-Z_{i}\right)-\Lambda\left(\delta_{2}-Z_{i}\right)\right] \frac{\partial Z_{i}}{\partial \chi_{i k}} \\
& =\left[-\Lambda^{\prime}\left(\delta_{3}-Z_{i}\right)-\Lambda^{\prime}\left(\delta_{2}-Z_{i}\right)\right] \beta_{k} \\
& \frac{\partial \operatorname{Pr}(Y=4)}{\partial X_{i k}}=\frac{d}{d_{z i}}\left[1-\Lambda\left(\delta_{3}-Z_{i}\right)\right] \frac{\partial Z_{i}}{\partial \chi_{i k}}=-\Lambda^{\prime}\left(\delta_{3}-Z_{i}\right) \beta_{k}
\end{aligned}
$$

\begin{tabular}{|c|c|c|}
\hline \multicolumn{2}{|c|}{$\begin{array}{l}\text { Symbol Corresponding variable } \\
\text { Used }\end{array}$} & \multirow{2}{*}{$\begin{array}{l}\text { Remarks } \\
i=1 \text { to } 4\end{array}$} \\
\hline$\overline{D_{i}}$ & $\begin{array}{l}\text { Ordered variable derived from } \\
\text { consumer degree of fresh milk } \\
\text { consumption }\end{array}$ & \\
\hline AGE & Age of the respondent & Continuous variable \\
\hline INC & Household monthly income & If $>30,000=1$ otherwise $=0$ \\
\hline HEP & $\begin{array}{l}\text { Health problems affect on fresh } \\
\text { milk consumption }\end{array}$ & If present $=1$ otherwise $=0$ \\
\hline ETH & Ethnicity & If Sinhalese $=1$ otherwise $=0$ \\
\hline $\mathrm{HHC}$ & Household composition & $\begin{array}{l}\text { If children }<7 \text { years are pre- } \\
\text { sent }=1 \text { otherwise }=0\end{array}$ \\
\hline EDU & Education level & $\begin{array}{l}\text { If never attend to school }=0 \text {, } \\
\text { if primary only }=1 \text {, if second- } \\
\text { ary only }=2 \text {, if tertiary }=3\end{array}$ \\
\hline HHS & Household size & Continuous variable \\
\hline GEN & Gender of the respondent & If male $=1$ otherwise $=0$ \\
\hline \multicolumn{3}{|c|}{$\begin{array}{l}\text { Explanatory variables to represent attitudes derived from factor } \\
\text { analysis }\end{array}$} \\
\hline$F_{l}$ & $\begin{array}{l}\text { Cost and usage related attitudi- } \\
\text { nal factor }\end{array}$ & Factor score \\
\hline$F_{2}$ & Sensory factor & Factor score \\
\hline$F_{3}$ & $\begin{array}{l}\text { Nutrition related attitudinal } \\
\text { factor }\end{array}$ & Factor score \\
\hline$F_{4}$ & $\begin{array}{l}\text { Fresh milk availability related } \\
\text { attitudinal factor }\end{array}$ & Factor score \\
\hline
\end{tabular}

Where,

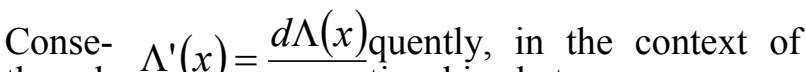
the rela- $\Lambda(x)=\frac{d x}{d x}$ tionship between consumers' degree of fresh milk consumption and their demographic, economic and attitudinal factors, the following empirical model was specified (Table 2).

$D_{i}=\beta_{0}+\beta_{1} * A G E+\beta_{2} * E D U+\beta_{3} * I N C+\beta_{4} * H H C+$ $\beta_{5} * H E P+\beta_{6} E T H+\beta_{7} * G E N+\beta_{8} * H H S$ $+\sigma_{1} * F_{1}+\sigma_{2} * F_{2}+\sigma_{3} * F_{3}+\sigma_{4} * F_{4}+\Sigma_{i}$

$$
D_{i}=Z_{i}+\Sigma_{i}
$$

\section{Table 2: Variables defined for the empirical model}


Table 3: Factor loadings, factor structure

\begin{tabular}{lll}
\hline Statement & Factor & Loading \\
\hline QPACK & Cost and usage $\left(\mathrm{f}_{1}\right)$ & .753 \\
HCOST & Cost and usage $\left(\mathrm{f}_{1}\right)$ & -.654 \\
BRAND & Cost and usage $\left(\mathrm{f}_{1}\right)$ & .630 \\
APEAR & Sensory $\left(\mathrm{f}_{2}\right)$ & .763 \\
TASTE & Sensory $\left(\mathrm{f}_{2}\right)$ & .734 \\
FTAST & Sensory $\left(\mathrm{f}_{2}\right)$ & -.550 \\
CONUE & Nutrition $\left(\mathrm{f}_{3}\right)$ & .747 \\
HINEU & Nutrition $\left(\mathrm{f}_{3}\right)$ & .678 \\
NEQUL & Nutrition $\left(\mathrm{f}_{3}\right)$ & .660 \\
PORAV & Availability $\left(\mathrm{f}_{4}\right)$ & .742 \\
ANYHW & Availability $\left(\mathrm{f}_{4}\right)$ & -.641 \\
\hline
\end{tabular}

\section{Data Collection and Questionnaire}

A questionnaire based survey was conducted with a sample of 115 randomly selected consumers to reflect various socio- economic characteristics during the period of April to June 2007.Questionnaire was pre- tested prior to the actual survey with a small sample of potential consumers $(n=20)$ and minor modifications were done to the preliminary questionnaire. The main survey was carried out in supermarkets, groceries, milk bars and retail shops at the areas of Kandy district.

11 attitude items were selected for inclusion in the survey questionnaire to reflect the four main themes of consumer interests in fresh milk, which are sensory factors, health and nutrition, cost and usage and availability (Caswell 1998; Wham and Worsley 2003).

Using Seven point "Likert scale", the frequency of fresh milk consumption was measured and responses were recorded as daily, occasionally, rarely or not at all.

\section{Data Analysis}

Ordered Logit (OLOGIT) via statistical package of STATA 8 was used to find out the respective relationships between the degree of fresh milk consumption and different demographic, economic and attitudinal factors of the individual consumers.

Estimates of log odds (Logits) cut off points and the probabilities derived for the independent variable of each model and marginal effects were used to interpret the nature of each explanatory variable and the relative size and sign of its effect.

\section{RESULTS AND DISCUSSION}

\section{Attitudes on Fresh Milk Consumption}

Factor analysis of the 11 individual attitude statements revealed four factors (Table 3 ). In the rotated factor matrix, factor 1 has high coefficients for variables, QPACK (packaging should be with high quality), BRAND (brand is a very important factor) and a negative coefficients for HCOST (always purchase products available in high price). There-
Table 4: Results of the ordered logistic regression

\begin{tabular}{llll}
\hline variable & Coefficient & $\begin{array}{l}\text { Standard } \\
\text { error }\end{array}$ & $(\mathbf{P}>|\mathbf{Z}| \mathbf{)}$ \\
\hline _cut 1 & 1.628743 & 1.196282 & \\
_cut 2 & 3.482099 & 1.231179 & \\
_cut 3 & 6.709388 & 1.3664 & \\
AGE & $0.078028 * * *$ & 0.0192923 & 0.000 \\
INC & $1.113861 * * *$ & 0.4788455 & 0.020 \\
HEP & $-.99913^{* * *}$ & 0.4417731 & 0.024 \\
ETH & $-.911044 *$ & 0.5515682 & 0.099 \\
HHC & $0.7119378 *$ & 0.3680675 & 0.053 \\
EDU & $0.63586 * * *$ & 0.2439572 & 0.009 \\
HHS & 0.0317115 & 0.1406498 & 0.822 \\
GEN & -.059374 & 0.4025507 & 0.883 \\
$F_{1}$ & $-7546678 * *$ & 0.2171081 & 0.001 \\
$F_{2}$ & $0.3406058 *$ & 0.2009153 & 0.090 \\
$F_{3}$ & $1.167511^{* * *}$ & 0.2433591 & 0.000 \\
F4 & $-5196215^{* * *}$ & 0.208212 & 0.013 \\
\hline
\end{tabular}

$* * *=$ Significance at $1 \%$ level, $* *=$ Significance at $5 \%$ level, $*=$ Significance at $10 \%$ level

fore, this factor was labelled as a cost and usage factor. Negative coefficient for negative variable leads to a positive interpretation and hence, consumers are reluctant to purchase products with higher price.

Factor 2 is highly related with variables, APEAR (appearance of the product is important), TASTE (taste is very important) and negative coefficient for FTASTE (fresh milk is more tasty than other processed milk products). Negative coefficient for negative variable leads to explain that fresh milk is not tastier than other processed milk products. Therefore, this factor was labelled as sensory factor.

Factor 3 is highly related with variables, CONUE (fresh milk is convenient source of many important nutrients), HINUE (always purchase milk products with high nutritional value) and NEUQL (nutritional quality of fresh milk is much higher than processed milk products). Thus, factor 3 may be labelled a Nutrition factor. Factor 4 has high coefficients for variables, PORAV (poor availability of fresh milk create me a barrier for consumption) and a negative coefficient for ANYHW (seek to purchase anyhow - without considering difficulties). This interprets consumer do not seek to purchase any how. Therefore, this factor was labelled as Availability factor (Table 3).

The categorization of the statements into these four factors is in line with the previous studies (Wham and Worsley 2003) where consumer attitudes were categorized in to sensory factors, cost and usage, health and nutrition and age and gender requirements.

As discussed previously, the attitudes (the four factors) were regressed with fresh milk consumption controlling for other socio economic and demographic variables. The ordered logistic regres- 
Table 5: Ordered dependent variable to represent to consumer frequency of fresh milk consumption

\begin{tabular}{llccc}
\hline Variable & $\begin{array}{l}\text { Frequency of } \\
\text { consumption }\end{array}$ & $\begin{array}{l}\text { Number of } \\
\text { consumers } \\
(\mathbf{n = 1 1 5})\end{array}$ & $\begin{array}{l}\text { Percentage } \\
(\%)\end{array}$ & Probability \\
\hline$Y=1$ & Not at all & 27 & 23.48 & \\
$Y=2$ & Rarely & 30 & 26.09 & 0.2435 \\
$Y=3$ & Occasionally & 43 & 37.39 & 0.2609 \\
$Y=4$ & Daily & 15 & 13.04 & 0.3652 \\
$\mathrm{Chi}^{2}$ & 83.61 & Probability & $(0.0000)$ & \\
$\chi^{2}$ & & & & \\
& & & & \\
\hline
\end{tabular}

sion carried out was found to be significant (Table 5). Thus, this latent variable was captured through identifying the frequency of consumption in the model. The cut off points estimated (Table 4) specify the ordinal likelihood rankings of the frequency of consumption.

Hence, if the latent variable $\mathrm{D}_{\mathrm{i}}$ takes the value less than 1.62, the ordinal dependent variable will take the value of 1(do not consume at all). If it is between 1.62 and 3.48 the ordinal dependent variable is 2 (consume rarely). If the $\mathrm{D}_{\mathrm{i}}$ is between 3.48 and 6.71 , the ordinal dependent variable will take the value of 3 (consume occasionally) and if it is more than 6.71 , the consumers consume milk daily (Table 4).

The estimated coefficients and standard errors reveal which factor influence respondents consumption intentions for fresh milk consumption. A statistically significant coefficient suggests that the likelihood of consumption of product will increase/ decrease as the response on the explanatory variable increase /decrease (Borooah 2002)

Table 6 shows that marginal effects of each explanatory variable on consumption probability of fresh milk. The marginal effects provide insights in to how the explanatory variables shift the probability of frequency of fresh milk consumption between the four ordinal levels. The following sections discuss the statistical significance of the coefficients and the marginal effects, particularly focusing on the lowest level of fresh milk consumption ( $\mathrm{Y}=1$ or not at all).

\section{Demographic Variables}

Results for demographic variables are helpful in profiling consumer who is likely to be most interested in fresh milk consumption. Ceteris paribus gender (GEN) and household size (HHS) did not have significant impact on fresh milk consumption. The age (AGE) effect shows that, ceteris paribus, increasing age is associated with an increasing probability of fresh milk consumption.

Ceteris paribus, Ethnic group (ETH) which is dummy variable (given $1=$ Sinhalese and otherwise $=0$ ) shows negative relationship with the probability of fresh milk consumption. This indicates peo-
Table 6: Marginal effects

\begin{tabular}{|c|c|c|c|c|c|c|c|c|}
\hline variable & $\mathbf{Y}=\mathbf{1}$ & $\overline{\mathrm{SE}}$ & $\mathbf{Y}=\mathbf{2}$ & $\overline{\mathrm{SE}}$ & $\mathbf{Y}=\mathbf{3}$ & $\overline{\text { SE }}$ & $Y=4$ & $\overline{\mathrm{SE}}$ \\
\hline$\overline{\mathrm{AGE}}$ & $-.008^{* * *}$ & .002 & $-.010^{* * *}$ & .003 & $.016^{* * *}$ & .004 & $.003^{* *}$ & .001 \\
\hline INC & $-.106^{* *}$ & .042 & $-.159 * *$ & .073 & $.210^{* * *}$ & .082 & $.055^{*}$ & .033 \\
\hline HEP & $.118^{* *}$ & .058 & $.126^{* *}$ & .056 & $-.206^{* *}$ & .091 & $-.037 *$ & .020 \\
\hline ETH & $.081 *$ & .041 & .135 & .084 & $-.169 *$ & .087 & -.047 & .039 \\
\hline $\mathrm{HHC}$ & $-.079 *$ & .042 & $-.098^{*}$ & .055 & $.150^{*}$ & .080 & $.027 *$ & .016 \\
\hline EDU & $-.071 * *$ & .029 & $-.087 * *$ & .038 & $.134 * *$ & .054 & $.024 * *$ & .012 \\
\hline HHS & -.003 & .015 & -.004 & .019 & .006 & .029 & .001 & .005 \\
\hline CEN & .006 & .045 & .008 & .055 & -.012 & .084 & -.002 & .015 \\
\hline$F_{1}$ & $.084^{* * *}$ & .027 & $.104 * * *$ & .038 & $-.159^{* * *}$ & .049 & $-.029 *$ & .012 \\
\hline$F_{2}$ & $-.038^{*}$ & .023 & -.046 & .029 & $.071^{*}$ & .043 & .013 & .008 \\
\hline$F_{3}$ & $-.130^{* * *}$ & .034 & $-.160^{* * *}$ & .049 & $.246^{* * * *}$ & .059 & $.045^{*}$ & *.017 \\
\hline$F_{4}$ & $.058 * *$ & .025 & $.071 * *$ & .032 & $-.109 * *$ & .045 & $-.020 * *$ & .010 \\
\hline
\end{tabular}

$* * *=$ Significance at $1 \%$ level, $* *=$ Significance at $5 \%$ level, $*=$ Significance at $10 \%$ level

ple who are Sinhalese, had lower probability for higher frequency of fresh milk consumption and a higher probability of being not consuming the fresh milk frequently. The significant and positive EDU shows that, increasing education level is associated with an increasing probability of fresh milk consumption. Furthermore, table 6 shows that the probability of fresh milk consumption increases with the household composition (HHC).

\section{Economic and Health Variables}

Results revealed that increasing income is associated with an increasing probability of fresh milk consumption, but people who had health problems had lower probability for higher frequency of fresh milk consumption, and a higher probability of being not consuming the fresh milk frequently. Past studies have found that even though, the consumers were made aware of the good health benefits and reducing risk for exposing to diseases, they have not increased the interest on dairy products (Peng et al 2006)

\section{Attitudinal Variables}

As far as attitudinal factor variables are concerned, the effect of cost and usage shows that increasing cost and usage factor is associated with a decreasing probability of fresh milk consumption. Bus and Worsley (2003) found out that respondents agreed that fresh milk is expensive and this may be a barrier to milk consumption, especially among people in lower income groups. Glenz et al. (1998) found out that after taste, cost was the most important influence on food choice. The study also showed that participants in a community wellness programme in the USA said they would drink more milk if it were less expensive.

Consumer attitudes about the availability factor of fresh milk appeared to have negative impact on their consumption which does not directly represent the availability. Furthermore, this factor showed a 
negative impact with consumption since it appears to represent the poor availability and difficulties occur due to poor availability.

Nutrition related attitudinal factors shows positive relationship with the fresh milk consumption, which means ceteris paribus increasing level of positive attitudes about nutrition value, is associated with an increasing probability of consuming the fresh milk frequently. Previous studies also found that $95 \%$ of consumers believe that certain foods have benefits that go beyond basic nutrition and may reduce the risk of certain diseases or improve their overall health. Although consumers are aware of such health benefits, they still evaluate all other product attributes based on their perception of taste, naturalness, appearance and price (Teratanavat and Hooker 2006)

Moreover sensory factor related attitudinal variable factor showed that positive relationship with the probability of fresh milk consumption is associated with an increasing probability of fresh milk consumption. According to Bus and Worsley (2003) taste is a major determinant of food choice. They found out that the more than $73 \%$ of consumers had positive attitudes towards the taste of milk. However, previous studies have shown that perception about taste of milk is influenced by the fat content. For example, preferred whole milk to skimmed milk, and that the sensory score fore liking increased with increasing fat content. Regulating grain dormancy and germination functioned by the involvement of many genes in the interconnected signal transduction pathway. Hence it may be difficult to visualize the effect of each and every gene phenotipically within the present range of GI or germination $\%$ even there is allelic differences exist between two parents. Moreover, hexaploid nature of the wheat genome has made the identification of such genes difficult. On the other hand this trait is highly sensitive to environmental factors. Therefore, phenotypic expression of the grain dormancy depends on the interaction between the expressed gene and environmental factors which can exist from development stage to maturation stage of the grain. Under such interactions and under the narrow range of phenotypic evaluation methods those QTLs may not be significant in the same way in every trial. The present study has investigated five putative novel grain dormancy QTLs which lead to the foundation for further breeding studies to practice effective marker-assisted selection aiming at producing PHS tolerant white-grained lines.

\section{CONCLUSION}

The findings of the study help to develop policies and marketing strategies which are most suitable to fit with the consumer expectations. The fresh milk marketing companies can modify their targeting strategies from undifferentiated to differentiate which will enable them to provide a better service and earn an outstanding profit.

Further findings of the study imply that fresh milk has become less relevant to peoples' lifestyle, and nutritional benefits of fresh milk are not widely understood. However, since negative attitudes to fresh milk were not existed, that may not limit the potential to make fresh milk an everyday part of modern life. The narrow focus of the perceived nutritional benefits of milk appears to have inhibited fresh milks' popular appeal. Moreover there are opportunities to provide target communication about the health benefits of milk.

This study experience that, different groups would react differently to the frequency of fresh milk consumption. People who are more interested in fresh milk consumption tend to have higher education and income levels. Furthermore there are opportunities to increase fresh milk consumption by reducing the price and increasing the quality simultaneously and the "market" can promote the consumption of fresh milk in Sri Lanka to a greater extent.

\section{ACKNOWLEDGEMENTS}

The authors wish to express their gratitude to acknowledge all the staff members of the Department of Animal Production and Health, Peradeniya. The principal author gratefully acknowledges the support of Department of Agribusiness Management and Computer Service Unit of the Wayamba University of Sri Lanka.

\section{REFERENCES}

Borooah VK 2002 Logit and Probit: Ordered and multinomial models. Series Quantitative Applications in the social science. No 138.Tousand Okas: Sage publications.

Bus AEM and A Worsley 2003 Consumers' Sensory and Nutritional Perception of three types of milk. Public Health Nutrition. 6.No2. 201208.

Caswell JA 1998 Valuing the benefits and costs of improved food safety and nutrition. Australian Journal of Agriculture and Resource Economics, 42: 4, 409-424. 
Central Bank of Sri Lanka 2005a Central Bank Annual Report. Central Bank of Sri Lanka, Colombo

Central Bank of Sri Lanka 2005b Economic and Social Statistics of Sri Lanka. Central Bank of Sri Lanka, Colombo.

Darby MR and E Karni 1973 Free competition and the optimal amount of fraud. Journal of law and economics. 16 (4). 67-88.

Glenz K, M Basil and E Maibach 1998 Why Americans eat what they do: taste, nutrition, cost, convenience and weight control concerns as influence on food consumption. Journal of American Diethetic Association. 10:1118-26.

Malhotra NK 2005 Marketing research, Marketing Research on Applied Orientation. $4^{\text {th }}$ edition. Georgia Institute of Technology Prentice - Hall of India

Massey LK 2001 Dairy food consumption blood pressure and stroke. Journal of Nutrition. 131 (7): $1875-8$

Ministry of Livestock Development and Rural Industry (MLDRI) 1995 Policy and Programmes. Ministry of Livestock and Rural Industry, Colombo, Sri Lanka

Ministry of Livestock Development and Estate Infrastructure (MLDEI) 2000 Policy strategy for dairy industry. Ministry of Livestock and Estate Infrastructure, Colombo, Sri Lanka
Nelson P 1970 Information and consumer behaviour. Journal of Political Economy. 78(2): 311329.

Pampel FC 2000 Logistic Regression: A Primer Series: Quantitative Applications in the Social Sciences. No 132. Thousands Okas. Sage Publications.

Peng Y, GE West and C Wang 2006 Consumer attitudes and acceptance of CLA- enriched dairy products. Canadian Journal of Agriculture Economics. 54, 663-684.

Schmid ND 2006 The Health Benefits of raw milk from grass fed animals. Available online at http://www.realmilk.com/healthbenefits.html (Retrieved July 24 2007).

Shaper AG, G Wannamethee and M Walker 1991 Milk, butter and heart disease. British Medical Journal.302:785-791

Teratanavat R and NH Hooker 2006 Consumer valuation and preference heterogeneity for novel functional food. Journal of food science. 71, pp 533-540

Wham CA and A Worsley 2003 New Zealanders' attitudes to milk: implication for public health. Public Health Nutrition. 6. No 1. pp 73-78.

Zemel MB 2002 "Regulation of adiposity and obesity risk by dietary calcium, Mechanisms and implications." Journal of American college of nutrition. 21(2): 146-151 